\title{
ADOÇÃO POR HOMOAFETIVOS COMO POSSIBILIDADE DE AMPLIAÇÃO DA CIDADANIA DAS CRIANÇAS E ADOLESCENTES ABRIGADOS
}

\author{
ADOPTION BY HOMOSSEXUAL PARENTS AS A \\ POSSIBILITY OF BROADENING THE CITIZENSHIP \\ OF ORPHANED CHILDREN AND TEENAGERS
}

\author{
MARIA CRISTINA RAUCH BARANOSKI ${ }^{1}$ \\ DANUTA ESTRUFIKA CANTOIA LUIZ²
}

\begin{abstract}
RESUMO: Este artigo se constitui numa síntese de pesquisa que teve como objetivo analisar a possibilidade de adoção de crianças/adolescentes por pessoas em uniões homoafetivas, como uma das alternativas de ampliação da cidadania-direito a convivência familiar e comunitária às crianças e adolescentes. A pesquisa teve caráter qualitativo e com o seguinte procedimento metodológico: sistematização de referencial teórico partir das categorias analíticas: cidadania, criança/adolescente; família; adoção; união homoafetiva, visualizando debate sobre a adoção por homoafetivos no Brasil, identificando perspectivas e caracterização da adoção como forma de proteção integral da criança/adolescente abrigados e o direito à convivência familiar e comunitária da criança/adolescente. Assim como, as dinâmicas das relações humanas que repensam os modelos de família. Na sequência, realizou-se a pesquisa de campo junto a sujeitos (profissionais do processo e militantes de movimentos e ONGs da categoria homossexuais e da adoção) que vivenciam a realidade pesquisada. Dos depoimentos colhidos, com entrevista semi-estruturada, foi possível realizar a síntese da coleta e interpretação dos dados, resultando na identificação de uma perspectiva positiva para a questão, mesmo que determinada estrutural e culturalmente, abrindo possibilidades e desafios à cidadania dos sujeitos envolvidos na questão.

PALAVRAS-CHAVE: Cidadania de Crianças e Adolescentes; Adoção de Pessoas em Uniões Homoafetivas.
\end{abstract}

ABSTRACT: This article aims to analyze the possibility of children's and adolescents' adoption for people in homo affective union, as one of the alternatives for the

\footnotetext{
Artigo recebido em 27.04.2013. Pareceres emitidos em 04.06.2013, 13.06.2013 e 25.11.2013. Artigo aceito para publicação em 07.04.2014.

${ }^{1}$ Professora Mestre, Doutoranda do Departamento de Direito Processual - Universidade Estadual de Ponta Grossa. cristinarauch@ibest.com.br

2 Professora Doutora do Departamento de Serviço Social - Universidade Estadual de Ponta Grossa.danutaluiz88@gmail.com
} 
extension of citizenship and of the right that children and adolescents have to a family and a community life. The search has a quantitative and qualitative character, being held through the following methodology: systematization of theoretical and methodological basis of the major analytical categories: citizenship, child and adolescent, family, adoption, homo affective unions. Through this search it's possible to visualize the debate on the homosexual adoption in Brazil, identifying prospects and characterization of the Institute of adoption as a mean of integral protection for children and adolescents that are on shelters. On this systematization, it was of fundamental importance the analysis on the children's and adolescents' rights to have a life in a family and community environment, and the dynamic of human relationships that result in a rethink on the types of family that already. In the process, it was performed a fieldwork research with the significant subjects who experience the reality studied (professionals and militants), through their testimonials about the prospects to expand the citizenship of children and adolescents and the adoption by people in homo affective unions. The synthesis of this process resulted in the identification of a positive outlook for the researched topic, even though it was structurally and culturally determined, opening up possibilities and challenges to children's citizenship.

KEYWORDS: Citizenship; Child and Adolescent; Adoption from People in Homo Affective Unions.

SUMÁRIO: Introdução; 1. As Categorias Analíticas; 1.1 Perfil dos Sujeitos Entrevistados; 1.2 Concepção de Cidadania; 1.3 Concepção de Família; 1.4 Crianças e Adolescentes Abrigados; 1.5 Adoção por Pessoas em União Homoafetiva; Considerações Finais; Referências Bibliográficas.

SUMMARY: Introduction; 1 . Analytical Categories; 1.1 Profile of Interviewees; 1.2 Conception of Citizenship; 1.3 Designing Family; 1.4 Sheltered Children and Adolescents; 1.5 Adoption from People in Homo Affective Unions; Conclusion; Bibliography.

\section{INTRODUÇÃO}

No Brasil, as lutas pela cidadania política e social têm, historicamente, avanços e recuos, muitas foram, e ainda são empreendidas pelos diversos movimentos e organizações sociais para a conquista dos preceitos democráticos previstos na Constituição Federal de 1988. Em termos de garantias fundamentais, falta muito para que os princípios que norteiam a Constituição Federal tornem-se realidade na vida dos brasileiros, pois, cidadania, contextualizada historicamente, "[...] como um processo de inclusão social dentro de específicos modos de produção da vida social [...]" (CORRÊA, 2002, p. 33), mostra que o Brasil deve evoluir mais, para galgar um patamar de país democrático em suas relações.

A cidadania se estabelece como a relação entre os pares, com efetiva e integral participação, faz parte de um processo que envolve a participação de vários segmentos de uma sociedade como membros integrais desta. Membros que enfrentam um contexto de relações sociais excludentes, em especial na trajetória brasileira, quanto ao reconhecimento dos direitos.

Neste contexto se situa a cidadania relacionada a questão da infância e juventude brasileira, a qual têm a marca das diferenças econômico-sociais. 
Crianças e adolescentes representam $34 \%$ da população brasileira, ou, 57,1 milhões de pessoas, donde $48,8 \%$ é considerada pobre ou miserável. (SILVA, 2004, p. 43).

Um dos objetivos do Plano Nacional de Promoção, Proteção e Defesa do Direito de Crianças e Adolescentes à Convivência Familiar e Comunitária (documento oficial que orienta as políticas e ações para as crianças e adolescentes no Brasil contemporâneo) é priorizar a recuperação do ambiente familiar, para que a família possa exercer seu papel na proteção e cuidado dos filhos. Deve estimular políticas públicas para que a criança ou o adolescente não precise ser retirado do convívio familiar, que pode ser contornada com compromissos políticos, voltados à inclusão social e ao apoio à família, num exercício de promoção da cidadania.

$\mathrm{Na}$ adoção surge o debate relativo às crianças e adolescentes que não estão no perfil solicitado pelos pretendentes. A maioria das crianças abrigadas são meninos de 7 a 15 anos, longe do estereótipo que marca os pedidos de adoção nacional: meninas brancas até dois anos.

Às crianças que não estão enquadradas na expectativa dominante do adotante, o que se reserva é a exclusão; por isso, emerge a necessidade da discussão da ampliação das possibilidades da adoção, de um lado, na perspectiva da qualidade de cidadãs das crianças e dos adolescentes, enquanto sujeitos participantes da realidade social, em condições de exigir o cumprimento das garantias conquistadas; de outro lado, na perspectiva da concepção de cidadãs das pessoas em uniões homoafetivas, interessadas em adotar.

Se a família contemporânea não está adstrita a uma imagem econômica ou de reprodução, mas sim, remodelada pelo amor, solidariedade, afeto e, pela possibilidade de se constituir em grupo familiar, os diferentes arranjos são possíveis, inclusive as uniões homoafetivas.

O reconhecimento dos direitos dos homossexuais, através da luta para reconhecer a sua cidadania e das uniões de pessoas do mesmo sexo como entidade familiar, coloca a discussão acerca da conjugalidade e da parentalidade dos homossexuais (MELLO, 2006, p. 4). O artigo $1^{\circ}$ da Constituição Federal estabelece, como principio basilar do Estado brasileiro, a dignidade da pessoa humana, o que equivale dizer que a democracia se expressa também na possibilidade de efetivar o princípio da dignidade dos homossexuais em uniões homoafetivas podendo adotar crianças.

Para efetivar os direitos da infância e juventude, previstos na Constituição Federal de 1988, foi promulgada a Lei 8.069/90 - Estatuto da Criança e do Adolescente, acontecimento que acarretou na tomada de consciência da necessidade de manter as crianças e os adolescentes junto à família, a princípio, de origem biológica ou, quando isto não é possível, na busca por uma família substituta, em especial, através do instituto da adoção.

A argumentação traçada neste artigo tem a família como base para o desenvolvimento integral da criança e do adolescente, seguindo as 
recomendações da Convenção das Nações Unidas pelos Direitos da Criança e do Adolescente e do Estatuto da Criança e do Adolescente. Considera o abrigo não como um fim em si mesmo, mas apenas como forma de proteção temporária para a criança ou adolescente sem família ou, afastada dela, porque, inadequada naquele momento para abrigá-la e suprir as suas necessidades básicas ${ }^{3}$.

O direito à convivência familiar e comunitária para crianças e adolescentes, mesmo após mais de duas décadas da promulgação do Estatuto da Criança e do Adolescente continua a preocupar, pois, muitas, após o abrigo, não conseguem voltar para as suas famílias de origem e não encontram espaço nas famílias inscritas para adoção.

Em 2006 formulou-se o Plano Nacional de Promoção, Proteção e Defesa do Direito de Crianças e Adolescentes à Convivência Familiar e Comunitária (BRASIL, 2006), colocando a necessidade da busca ativa ${ }^{4}$ de famílias que possam ter interesse em dar um lar a estas crianças e adolescentes.

No contexto da discussão sobre a busca ativa de famílias para as crianças e adolescentes, realizou-se uma pesquisa no programa de mestrado em Ciências Sociais e Aplicadas na Universidade Estadual de Ponta Grossa, no período de 2008-2009, que teve como analisar as possibilidades da adoção de crianças e adolescentes por pessoas em uniões homoafetivas, como uma das alternativas para a efetivação do seu direito à convivência familiar e comunitária.

O presente artigo traz uma síntese dos dados coletados na pesquisa de campo no sentido de contribuir com o debate que vem ocorrendo em nível nacional sobre a questão da adoção em uniões homoafetivas.

Para buscar o alcance do objetivo traçado no processo de pesquisa, os procedimentos metodológicos realizados foram de caráter qualitativo iniciando pela sistematização do referencial teórico ${ }^{5}$, a partir das categorias analíticas, quais sejam: cidadania; criança e adolescente; família; adoção; união homoafetiva. Os principais autores consultados para essa etapa foram: Marshal (1967); Uziel (2007) e Groeninga (2008); sem prejuízo de outros, bem como, o Plano Nacional de Promoção, Proteção e Defesa do Direito de Crianças e Adolescentes à Convivência Familiar e Comunitária (2006).

Com o referencial visualizou-se o debate sobre a adoção por pessoas em uniões homoafetivas no Brasil contemporâneo, identificando perspectivas

\footnotetext{
${ }^{3}$ Não se pretende sacralizar a família, algumas, podem sim representar perigo a formação da criança ou do adolescente, assim o abrigo irá representar a segurança que ela necessitará naquele momento, porém, sempre pautando pela permanência provisória.

4 "Busca ativa: ato de buscar famílias para crianças e adolescentes em condições legais de adoção, visando garantir-Ihes o direito de integração a uma nova família." (BRASIL, 2006, p. 134)

${ }^{5}$ Pelos limites e objetivos deste artigo, não consta o texto do referencial teórico sistematizado que referendou a pesquisa de campo. O Capítulo da dissertação originária deste artigo, que contém tal referencial está disponível em <http://bicen-tede.uepg.br/tde_busca/arquivo.php?codArquivo=462>.
} 
e a caracterização do instituto da adoção como forma de proteção integral da criança e do adolescente abrigados.

Solidificada a base teórico-conceptual foi realizada a pesquisa de campo, para poder lançar o olhar sobre uma realidade específica a ser pesquisada, a partir dos sujeitos que a vivenciam e que foram selecionados em razão de serem profissionais de diferentes áreas e atuantes nas categorias pesquisadas, o que tornou os depoimentos prestados, essenciais para o esclarecimento do assunto em foco (BARANOSKI, 2011, p. 82). A coleta de dados se deu através da realização de entrevistas semiestruturada com 8 sujeitos: 3 militantes de GAAs; 1 pai adotivo homossexual; 1 mãe adotiva heterossexual; e 3 profissionais ligados ao processo judicial da adoção (1 Magistrado, 1 Ministério Público e 1 técnico auxiliar do Judiciário).

Os oito sujeitos de pesquisa foram escolhidos entre profissionais de diferentes áreas e atuantes nas categorias pesquisadas (criança/adolescente; adoção; homossexuais), o que tornou os depoimentos prestados, essenciais para o esclarecimento do assunto em foco.

A escolha contribuiu para a perspectiva interdisciplinar da pesquisa. Para Martinelli (1994, p.12), a "[...] visão transdisciplinar ou interdisciplinar da prática social [...]" reforça a convicção de que "[...] o saber não é posse individual de cada profissão, é heterodoxo, é pleno, é encontro de signos [...]" por isso a "[...] produção de práticas sociais que tenham a dimensão do coletivo [...]" prescinde de diálogo com múltiplos saberes.

$\mathrm{Na}$ pesquisa qualitativa, conforme Martinelli (1994, p. 13), a coleta de dados privilegia o contato do pesquisador com o sujeito, e este, conectado em sua estrutura, deixará o pesquisador "entender os fatos a partir da interpretação que faz dos mesmos em sua vida cotidiana", partindo do pressuposto da singularidade do sujeito e da importância em conhecer a sua experiência social, assim, esse sujeito fará parte da construção coletiva da pesquisa.

Destaque aos profissionais ligados ao processo judicial da adoção, em especial o Magistrado e o Ministério Público. O primeiro, representante do Poder Judiciário, e o segundo, considerado, especialmente após a Constituição Federal de 1988 como detentor de um novo papel, especialmente na área da Infância e Juventude, quando assume proporções muito maiores e amplia sobremaneira o contato do Promotor de Justiça com a sociedade, o que o torna ator social ativo das políticas públicas e das ações empreendidas em nível municipal. (SANTA CATARINA, 2008, p. 7)

O Magistrado por sua vez exerce o Poder do Estado, e não deixa de ser um ator social de políticas públicas, não podendo deixar de entender que cada decisão proferida em um processo, tem o impacto social onde exerce a jurisdição, e mais, pode ainda fazer jurisprudência, ou seja, suas decisões, somadas, tem uma função criadora que preenche lacunas existentes nas leis, logo, a visão de um magistrado, é a consideração do Poder. 
As entrevistas ocorreram a partir de questionamentos relativos à: profissão; tempo de exercício e experiência com a adoção; concepções de cidadania e família; análise da situação da criança e do adolescente abrigados e possíveis alternativas; posição sobre a possibilidade da adoção por pessoas em união homoafetivas, bem como, se ocorre relação entre as categorias: cidadania, adoção e adoção por homoafetivos, ficando livre o sujeito para fazer considerações.

Após a coleta dos dados, iniciou-se a organização e análise do material à luz da pesquisa bibliográfica e documental, através de análise de conteúdo, posto que a técnica utilizada somente adquirirá força e valor "[...] mediante o apoio de determinado referencial teórico [...]" (TRIVIÑOS: 1987, p. 159).

Com a transcrição literal, identificando-se as categorias empíricas, e a partir das questões das entrevistas foram organizadas as seguintes categorias analíticas: perfil e experiência com adoção; concepções de cidadania; família; crianças e adolescentes abrigados; adoção homoafetiva e a relação cidadania/ criança e adolescente/adoção homoafetiva. Desta forma, organizou-se a sequência do artigo apresentando a síntese da análise realizada a partir das categorias analíticas da pesquisa realizada.

\section{AS CATEGORIAS ANALÍTICAS}

\subsection{Perfil dos Sujeitos Entrevistados}

Em síntese, 100\% têm experiência com a temática adoção, seja pelo envolvimento profissional como é o caso dos profissionais atuantes no processo de abrigamento e adoção; ou em razão da maternidade/paternidade homo e heterossexual; ou mesmo, como militantes dos GAAs, que assumiram o debate da temática da adoção ${ }^{6}$.

Os militantes, em número de três, integram os GAAs, possuem envolvimento e experiência com o tema por volta de trinta anos e um deles, tem duas filhas adotivas. A mãe adotiva traz um diferencial: os irmãos do seu filho foram adotados por homoafetivos, assim, seu envolvimento e vivência, diz respeito ao tema central da pesquisa. O pai adotivo é homossexual, detalha a experiência da adoção de duas crianças em agosto de 2007, além da experiência em programas de apadrinhamento, o que valoriza e deixa a pesquisa com maior aprofundamento sobre o tema.

O Juiz, o Assistente Social e o Ministério Público, tem a missão de, direta ou indiretamente influenciar no futuro daquele cuja adoção foi requerida. Parte do Judiciário a decisão de ser efetivada a adoção ou não, daí a importância do debate com estes profissionais, para entender a dinâmica emprestada ao processo de adoção. Ainda, o Juiz e o Ministério Público, são vistos como

\footnotetext{
${ }^{6}$ O sigilo foi uma das cláusulas pactuadas com os sujeitos entrevistados, e, para mantê-lo, foi adotado o seguinte código: S1, S2 e S3 para os militantes dos GAAs; S4 - Juiz; S5-Ministério Público; e, S6 - representante corpo técnico da Vara da Infância e Juventude; S7 - mãe adotiva; e, S8 - pai adotivo homossexual.
} 
atores sociais ativos de políticas públicas, conforme já exposto, o que impacta os depoimentos destes sujeitos na pesquisa qualitativa.

Caracterizados os sujeitos, buscou-se desvendar as perspectivas do debate sobre a adoção por homoafetivos, identificando as concepções de cidadania, família, crianças e adolescentes abrigados e adoção por homoafetivos como possibilidade de ampliação da cidadania da criança e do adolescente.

\subsection{Concepção de Cidadania}

$\mathrm{Na}$ análise foram separados pontos recorrentes da fala dos sujeitos, como: acesso, garantia e igualdade de exercício dos direitos; democracia e dignidade da pessoa humana.

Para $100 \%$ dos entrevistados, ocorre a menção de acesso a direitos enquanto concepção de cidadania; $87,5 \%$ somam o acesso a direitos, a garantia de seu exercício; aparecendo ainda em 12,5\%, a categoria igualdade; $12,5 \%$; democracia e $25 \%$ fazem referência à dignidade da pessoa humana, como concepções de cidadania.

Para a totalidade dos sujeitos, cidadania é "direito a ter direitos" (DAGNINO, 2000, p. 82), mas, não é só, é também ter esses direitos "garantidos efetivamente [...] é garantir em todos os aspectos para que ele tenha condições de exercer cidadania" (S6).

Não obstante parecer, na quantificação dos dados, que um dos sujeitos não fez a menção específica à garantia do exercício dos direitos, ainda assim, no contexto da fala deste sujeito tem-se subtendido que assim entende, quando afirma: "Todas as pessoas, desde a criança ao idoso, tem o mesmo direito" (S4).

A análise da concepção: "todas as pessoas" têm "direito a ter direitos" deve ser feita tendo como pano de fundo o modelo da relação social existente no país. O exercício da cidadania não é garantido apenas com a prescrição das normas, o modelo de relação econômica dita a possibilidade do acesso e exercício dos direitos prescritos. A garantia de exercício implica no reconhecimento de que numa sociedade de marcante desigualdade material, própria do sistema capitalista, como é o caso da sociedade brasileira, há "uma relação conflitiva entre liberdade política e igualdade social" (CORREIA, 2002, p. 216).

Para um dos entrevistados cidadania "É algo que recebemos pronto por estarmos inseridos numa sociedade. Logo temos direitos e deveres. Mas para que cada um possa se tornar um cidadão é necessário um trabalho subjetivo" (S5), ou seja, um "trabalho pessoal e interno" pode corresponder ao fundamento teórico de que para ser e estar cidadão há necessidade de cada indivíduo construir novas relações e elevar patamares de consciência.

A consciência enquanto poder de decidir e de percepção dos significados do ambiente em que vive, é parte integrante do indivíduo e, como componente definidor de suas ações, quando focalizado no exercício da cidadania, é a 
possibilidade de estabelecer os conceitos e a forma de ação do sujeito frente às suas relações sociais, que se constrói através da educação para a participação bem como também nas práticas políticas que possam garantir o exercício dos direitos assegurados, ou, nas palavras de um dos entrevistados, "Cidadania, ela deve ser respeitada, deve ser valorizada. [...] conquista, e a gente tem que preservar, só se preserva exercitando-a [...]", ou seja, construir cidadania é também construir novas relações e elevar patamares de consciência e, conforme aparece na definição, enquanto conquista, deve ser respeitada e valorizada, o que somente se consegue com o exercício de ser cidadão, ou seja, com a "predisposição do cidadão para intervir (SANDOVAL, 1994, p. 68).

Entre outras categorias que emergiram dos depoimentos, está a cidadania condicionada a dignidade da pessoa humana, "é o direito/dever [...] e o compromisso deste para garantir o atendimento de suas necessidades fundamentais, asseguradas pela Constituição do país" (S1), ou, "é todo esse conjunto [...] o que você faz e o que você vive está envolvido [...] na cidadania" (S8), e é a dignidade da pessoa humana (S6), para estes, cidadãos são aqueles que tem os direitos, o exercem em condições de igualdade, através de relações estabelecidas dentro da sociedade, como forma de cumprir o preceito fundamental da dignidade da pessoa humana.

A concepção de cidadania, para os sujeitos, coincide com a de Marshall (1967, p. 62), para quem a cidadania deve ser entendida como uma forma de viver que brota de dentro do indivíduo e não lhe é colocado ou imposto.

Os conteúdos das entrevistas, à luz das concepções teóricas, definem como ingredientes básicos da cidadania: os direitos; o acesso; a participação; o sentimento de pertencimento que media as relações; e, como demonstrou a análise teórica e as respostas dos sujeitos, não existe uma única concepção de cidadania, existe sim, uma construção, que se faz na convivência social, e que está constantemente se complementando e transformando e mostram que ser cidadão está além de ter direitos inscritos.

\subsection{Concepção de Família}

Um dos objetivos da pesquisa consiste em tentar compreender se ainda persiste uma concepção unânime de família nuclear, ou, se o repensar é a estratégia para acompanhar as pluralidades de organizações humanas que vem tendo visibilidade.

Neste contexto de pluralidades e da afirmação do afeto como princípio norteador do direito de família é que a entidade formada por pares de homossexuais pode ser defendida enquanto entidade familiar.

Inúmeras são as formas de se referir à família pelos sujeitos, que iniciaram com a concepção de família biológica, "um pai, uma mãe, os filhos, os avós, todo esse núcleo" (S7), e passam a aceitar outras concepções: "pessoas com laços de afeto" (S6), para outros, "não deixa de ser família [...] homens, solteiros, mulheres também, mães [...]" (S7); mas, a concepção recorrente encontra amparo no "grupo de pessoas que decidem viver em comum, muitas 
vezes sob um mesmo teto, durante um longo lapso de tempo e assumem o compromisso mútuo de proteção, afeto e geralmente de manutenção" (S1).

Afeto e respeito estão na fala dos sujeitos como determinantes da concepção de família, e coincide com Groeninga (2008, p. 21) que entende família como "a sede da formação da pessoa, de sua dignidade e personalidade", tendo por finalidade "propiciar o desenvolvimento, no ser humano, de sua capacidade de pensamento, em sintonia com os sentimentos" (GROENINGA, 2008, p. 27).

Quando o sujeito responde à concepção de família como a "única estrutura social que temos contra a globalização" e ainda "o único reduto social onde a singularidade pode ser respeitada e onde a cidadania pode ser recuperada" (S5), extrai-se a importância da família enquanto relacionadas as suas funções, "Dada a dependência e o desamparo emocional, que são da natureza humana, a função da família, embora sofra variações históricas, mantém-se essencialmente como instituição estruturante do indivíduo" (GROENINGA, 2008, p. 27).

A delimitação de quem exercerá as funções paternas e maternas dentro da família não se define pela condição homem e mulher e sim, pela forma de participação na dinâmica familiar. Ao adotar-se o conceito de parentalidade, o paradigma de que, somente o homem é o pai e a mulher é a mãe, fica destruído. As funções de pai e de mãe podem ser realizadas por qualquer pessoa que esteja desenvolvendo o papel de cuidar da criança.

A paternidade, na sociedade ocidental, para Grossi $(2009)^{7}$, tem conceito ligado ao pai, e corresponde a uma figura masculina. Com a parentalidade, a noção de paternidade, enquanto função é ampliada para ser exercida não só pelo pai, mas também por outras pessoas. Na "paternidade tradicional, existiam duas funções que se completavam e que nunca eram feitas pela mesma pessoa", assim a função de cuidar era da mãe e a de prover do pai, e o conceito de "parentalidade veio contribuir pra entender o momento atual, onde tais funções deixaram de estar associadas à idéia de que só o homem é pai e apenas a mulher é mãe". A importância das funções paternas e maternas são destacadas por um dos sujeitos: "Acompanhei em abrigos estas funções serem delimitadas com muita beleza; professores ou freiras fazendo a função materna e juízes e técnicos dos juizados fazendo a função paterna, um precisa do outro." (S5)

Groeninga (2008, p. 28) expõe que as funções paternas e maternas não dependem "exclusivamente do sexo biológico e da paternidade e maternidade biológicas", ressalta que existe em todo ser humano um componente de bissexualidade, "o que possibilita a todos os recursos de personalidade de ambas as ordens: do feminino e do masculino."

\footnotetext{
${ }^{7}$ Entrevista com Mirian Pillar Grossi concedida por telefone à IHU On-line - Revista do Instituto Humanitas Unisinos, em 02.03.2009.
} 
A reflexão sobre as uniões existentes na sociedade, que servem como: um "lugar de acolhimento, paz e harmonia" (S4); onde as pessoas podem "crescer por dentro, lapidar arestas, evoluir" (S3), impõe incluir a união homoafetiva na concepção de família.

\subsection{Crianças e Adolescentes Abrigados}

A família é, não só necessária como fundamental ao desenvolvimento do ser humano, portanto, outro tema deve ser abordado: crianças e adolescentes abrigados e, possíveis alternativas para garantir a convivência familiar e comunitária.

Por muitos séculos a relação de adultos e crianças ficou aquém dos laços afetivos que hoje são desenhados. Numa realidade recente (1950) existiu no Brasil a Roda dos Expostos como forma oficial de "transformar crianças abandonadas em filhos do Estado" (WEBER, 2000, p. 30). Atualmente, com o abandono de milhares de crianças nas ruas, mantém-se a existência oficiosa da Roda dos Expostos, resultando na "tradição de se abrigar crianças e adolescentes desvalidos" (S1).

Para o ECA - artigo 19 - toda criança ou adolescente tem direito de ser criado e educado no seio de sua família. A colocação em família substituta é feita em caráter excepcional.

Na pesquisa, 50\% dos sujeitos afirmam que: "Quando de curta duração, o abrigamento pode representar proteção para momentos de crise enquanto uma solução alternativa é construída" (S3). A ressalva do caráter provisório do abrigo ocorre, porque, na prática, o abrigo transforma-se em permanente, e a pobreza $^{8}$ é o fator que tem maior percentual da motivação para o abrigamento. A correção desta distorção somente pode ocorrer se políticas públicas adequadas e efetivas forem tomadas para sanar o problema da miséria.

Os eventuais resultados das políticas adotadas para coibir o abrigamento em razão da miséria, não ocorrem em curto prazo, consequência disto, é o abrigamento de longa duração ou, a exclusão dos "miseráveis" do convívio social, para os sujeitos: "quando de longa duração representa a negação de direitos podendo levar à exclusão social e à privação de direitos" (S3), apresentando alternativas para a garantia do direito à convivência familiar, propondo atitudes do Estado, através de políticas públicas adequadas às necessidades das famílias e das crianças e adolescentes abrigados; alguns apontam, em conjunto com o Estado, o compromisso da Sociedade, criando-se "mecanismos de acompanhamento e pressão social para que medidas sejam tomadas para evitar que crianças e adolescentes sejam esquecidos nos abrigos" (S3); "apadrinhamento afetivo" (S7); ou, a "busca de lares adotivos" (S4).

O Estado é apontado por $87,5 \%$ dos sujeitos, enquanto responsável pela efetivação das políticas públicas como o responsável pelo resgate das famílias

\footnotetext{
${ }^{8}$ Pesquisa realizada pelo IPEA - Instituto de Pesquisa Econômica Aplicada. Disponível em: $<$ www.http//ipea.gov.br>. Acesso em: 25 jul. 2008.
} 
em situação de miséria, para que estas famílias possam receber novamente suas crianças e adolescentes.

Ou seja, a democracia no Brasil só pode prosperar se enfrentar o desafio histórico de reverter a extrema desigualdade social. Para Rousseau o pacto social firmado num contexto de extrema desigualdade é um engano, um instrumento de opressão. Pensar as possibilidades de democracia no Brasil exige considerar a complexidade da sociedade atual e os mecanismos plurais de formação de consensos. (COSTA, 2006, p. 110).

Ultrapassar os obstáculos impostos pelas particularidades sócioeconômicas brasileiras na afirmação de uma cidadania inclusiva, participativa, impõe possibilitar a "autonomia da vida dos cidadãos" (WANDERLEY, 2002, p. 25). A elaboração do plano nacional de convivência familiar e comunitária apresenta um aceno positivo às possibilidades de mudança de uma realidade excludente, mas, requer uma mobilização "que deve ser coletivo e articulado na efetivação de direitos, tornando efetiva a participação social e, sobretudo, possibilitando o avanço na promoção, proteção e defesa do direito à convivência familiar e comunitária". (BRASIL, 2006, P. 19)

A adoção, para os sujeitos, é o caminho esperado para as crianças e adolescentes abrigados, sem condições de voltar à família de origem, "[...] a adoção é medida definitiva que coloca a criança na família substituta [...]." (S6)

Mas, como promover as adoções para garantir o direito à convivência familiar e comunitária à criança e ao adolescente que não conseguiram voltar às sua família de origem? Ainda: como promover esse direito quando a maioria das crianças e dos adolescentes abrigados não está no "padrão" das famílias que estão dispostas a adotar?

O princípio de proteção integral implica em entender que "a criança não existe para acertar a situação do casal, o casal existe para acertar a situação da criança" (S7), ou melhor, o interesse que movimenta a adoção é localizar uma família para a criança ou o adolescente, e não satisfazer o desejo pessoal dos adotantes.

O debate e a visibilidade da situação dos abrigados talvez seja o início de uma "nova cultura" na sociedade, enquanto agente também responsável por esta situação, pois, sendo "filhos de todos, a sociedade e o estado devem se responsabilizar, adotar estas crianças e tentar recuperar o laço de amor que funda a cidadania" (S5).

A participação e a discussão, em eventos promovidos pelos GAAs já mostram resultados segundo um militante: "[...] Essas discussões vem alcançando alguns resultados com a aprovação do Plano Nacional de Convivência Familiar e Comunitária (dez/2006) e com a Lei da Adoção a ser aprovada no Congresso Nacional.." (S1).

As concepções de cidadania, família, criança e adolescente para os pesquisados se aproximam na medida em que relacionam a categoria 
cidadania com o acesso e garantia de exercício dos direitos; crianças e adolescentes abrigados como excluídos da cidadania e família, enquanto pessoas unidas pelos laços da afinidade, ajuda e respeito mútuo, concepções essas que iluminarão as práticas, procedimentos e possíveis posições que os mesmos têm sobre a ampliação de cidadania e a adoção por homoafetivos.

\subsection{Adoção por Pessoas em União Homoafetiva}

Estabelecido que os abrigados estão excluídos da sua condição de cidadãos porque tem o seu direito fundamental de convivência familiar e comunitária violados, soluções devem ser encontradas para o resgate desta cidadania, a adoção é uma delas, senão, a única: "[...] quando a criança está com todos os seus direitos violados, a alternativa da cidadania dela é a adoção. [...]" (S6).

Verifica-se que $87,5 \%$ dos sujeitos acompanham o debate e são favoráveis a adoção por homoafetivos; $100 \%$ demonstram a preocupação com 0 atendimento prioritário do interesse da criança e do adolescente, "Na adoção o que deve ser considerado prioritariamente é o interesse da criança e do adolescente e qualquer pessoa ou casal deve ser avaliado em seus propósitos de "assumir filho."(S1)

Ressalvas à adoção por homoafetivos constaram das falas, emergindo a categoria preconceito em $50 \%$ das respostas, destas, $25 \%$ atribuem o preconceito das autoridades para com o processo e $25 \%$ o preconceito da própria sociedade para com os homoafetivos, emergindo, da análise dos depoimentos, categorias empíricas, quais sejam: valores e preconceito, além das funções: paterna e maternas.

Preconceito é o "uso típico refere-se a julgamentos categóricos, antecipados que têm componentes cognitivos (crenças, estereótipos), componentes afetivos (antipatia, aversão) e aspectos avaliatórios ou volitivos" (LESSA, 1996, p. 602). Pode gerar discriminação, violência, marginalização, pois se algo é diferente ou desconhecido, a disposição é entender que isto não é correto, porque não se enquadra nos padrões dominantes.

Os militantes dos GAAs e pais adotivos manifestaram a preocupação: risco que existe é o do preconceito das autoridades definidoras no processo[...]" (S1). A constatação implica num importante eixo de análise enquanto definidor da possibilidade da adoção por homoafetivos, pois, "muitas vezes é através do judiciário que se obtêm ganhos dos quais, a legislação só vai se ocupar mais tarde, o que reforça ainda mais a responsabilidade dos pareceres e das decisões." (UZIEL, 2007, p. 86),

A preocupação com o preconceito da sociedade veio dos sujeitos que atuam no processo judicial da adoção, preocupação que implica na posição de receio pela adoção por homoafetivos: "dois problemas que vão se unir. [...] a questão do homossexual, [...] preconceito da não aceitação por parte das pessoas, [...]" (S8). O sujeito chega a afirmar que em razão da relação de 
conflito da adoção por homoafetivos, a criança ou o adolescente, nestas condições, não teria a cidadania plena, pois sofreria preconceito.

Percebe-se nas passagens dos depoimentos dos sujeitos que atuam no processo da adoção, respostas, sem assumir uma atitude contra explicitamente, e num dos depoimentos, ocorre a espera de uma resposta "de fora": "...precisa trabalhar bem essas questões [...] precisa pensar em como ajudar, a debater [...]" (S8), indicando que o sujeito não tem uma posição definida.

Outro sujeito restringe idade da criança para a adoção por homoafetivos: "[...] aceito a habilitação de casais homossexuais [...] desde que a pessoa a ser adotada tenha 12 anos ou mais" (S6), justificando "legalmente" a restrição: [...] já tem condições de dizer se pra ele vai ser bom, se ele concorda com aquela situação [...]" (S6). O que transpareceu da colocação foi um receio de assumir uma decisão com poucos precedentes, e, na adoção de adolescentes, ele também participará e assumirá parte da responsabilidade da adoção. O sujeito deixa uma explicação: a de que não tem base técnica para o deferimento da adoção para os homoafetivos para crianças, mas aceita que "daqui 20 anos pode mudar [...]" (S6).

A posição do judiciário mostrou timidez. Parece que há um receio na tomada de uma atitude que possa desestruturar os valores que estão agregados no convívio social, o que pode sinalizar um recuo, pois o judiciário é um dos responsáveis pelos ganhos em termos de reconhecimento da cidadania, obtidos pela sociedade.

A pesquisa de campo realizada, especialmente em relação Judiciário e Ministério Público, demonstrou o que já é percebido nos tribunais de longa data: a luta incessante pelas famílias homoafetivas pelo acesso aos direitos decorrentes de sua qualidade de cidadãos que, no Judiciário ocorre há muito tempo, mas somente nos tempos mais recentes o reconhecimento surge.

O (des)compasso da jurisprudência, seus avanços e recuos ocorre em razão do "[...] vazio legal no trato da dimensão familiar dos vínculos afetivosexuais para os homoafetivos, o que faz com que ora seja afirmada, e, ora seja negada [...]" (MELLO, 2006).

A $1^{\text {a }}$ decisão judicial referente a adoção se deu em 05.07.2005, pelo Juiz de Direito Júlio César Spoladore Domingos, da Comarca de Catanduva-SP, que habilitou um candidato e seu companheiro à adoção; sendo a adoção efetivada em 30 de outubro de 2006, pela Juíza Sueli Juarez Alonso ${ }^{9}$.

Depois deste fato, em novembro de 2005, o juiz da Vara da Infância e da Juventude de Bagé-RS, Marcos Danilo Edson Franco, concedeu a adoção de duas crianças a um casal de mulheres que mantém relação homoafetiva. As meninas são irmãs biológicas e cada uma delas já tinha sido adotada por uma das parceiras, confirmado em 05 de maio de 2006, pelo Tribunal de

\footnotetext{
${ }^{9}$ Disponível em: <http://www.jornalocal.com.br/noticias/?id=1359>. Acesso em 20 jul. 2009.
} 
Justiça do Rio Grande do Sul, através do acórdão 70013801592, da $7^{\text {a }}$ Câmara Cível, onde foi relator o Desembargador Luiz Felipe Brasil Santos ${ }^{10}$.

Da mesma forma ocorreu em 2008, quando o Juizado da Infância e da Juventude de Recife-PE, deu sentença favorável ao pedido de adoção de duas irmãs -de cinco e de sete anos- feito por um casal homossexual masculino que vive em Natal- $\mathrm{RN}^{11}$; em 2009, quando a Justiça gaúcha, em Viamão - RS, reconheceu a paternidade de um empresário gaúcho, para um menino de 11 anos que estava registrado em nome apenas do companheiro que faleceu em 2008. A criança foi adotada há quatro anos, enquanto que a união homoafetiva manteve-se por 10 anos. Por ocasião da adoção, somente um dos companheiros fez o pedido, porém, em junho do ano de 2008, os homoafetivos peticionaram requerendo o reconhecimento da paternidade para ambos, sob o argumento de que, juntos, educavam e mantinham financeiramente a criança, porém em agosto do mesmo ano, o pai adotivo morreu, mas o outro companheiro pediu o prosseguimento da ação. A sentença foi proferida pelo juiz José Antonio Daltoé Cezar, da $2^{\mathrm{a}}$ Vara da Infância e Juventude de Porto Alegre, e a criança passou a ter o sobrenome dos dois pais, e na certidão de nascimento, conta os quatro avós, sem especificar quem são os avós paternos ou maternos, e a palavra "mãe" não aparece no registro. Com isto, possibilitou à criança o direito à herança dos dois pais. ${ }^{12}$

De mesmo conteúdo, outros precedentes judiciais ocorreram em Santa Catarina, Paraná e Distrito Federal, por exemplo, assegurando a permanência no país de estrangeiros companheiros de homossexuais brasileiros, porém, decisões isoladas.

No final de $2008^{13}$ o Superior Tribunal de Justiça decidiu que a Constituição não proíbe expressamente a união estável entre pessoas do mesmo sexo. Assim, abriu a possibilidade para que homossexuais formem uma família; e, mais recente, no ano de 2010, o Supremo Tribunal Federal, no recurso extraordinário que teve como relator o ministro Marco Aurélio de Melo, garante o direito de união homoafetiva em cadastrar-se perante os registros de adotantes, em conjunto, sem limitação de sexo ou idade da criança ou adolescente. Saliente-se que esta decisão foi oriunda justamente da negativa do recurso interposto pelo Ministério Público que postulava pela manutenção da sentença de $1^{\circ}$ grau (proferida pelo Juiz de Direito) deferindo inscrição da habilitação dos pretendentes à adoção, homoafetivos, com restrições em relação ao adotante, desde que a partir dos 10 anos, e do sexo feminino, uma vez que os pretendentes eram do sexo masculino.

\footnotetext{
${ }^{10}$ Disponível em: <http://www.tjrs.jus.br/site_php/consulta>. Acesso em: 19 jul. 2009.

${ }^{11}$ Disponível em: <http://www1.folha.uol.com.br/f>. Acesso em: 10 nov. 2008.

${ }^{12}$ Disponível em: <http://www.oabpg.org.br/noticias>. Acesso em: 04 fev. 2009.

${ }^{13}$ Recurso Especial no 820.475 - RJ $(2006 / 0034525-4)$ da $4^{a}$ Turma do Superior Tribunal de Justiça, julgamento de 02.09.2008. Disponível em: <http://.stj.jus.br>. Acesso: em 02 out. 2008.
} 
Não obstante as decisões positivas proferidas pelo Superior Tribunal de Justiça e pelo Supremo Tribunal Federal, que não têm efeito vinculante, o reconhecimento da união homoafetiva como entidade familiar depende do juiz do feito, o que gera insegurança aos cidadãos homossexuais que precisam exigir na Justiça o reconhecimento e a efetivação de seus direitos.

Neste sentido, os depoimentos dos sujeitos refletem as nuances das decisões apresentadas, no contexto de uma cidadania reguladora, que não percebe as diferenças existentes na sociedade, necessitando redefinir este conceito para uma cidadania emancipatória, com base em noções inclusivas, que visa reconhecer e respeitar as diferenças, as diversas expressões de vida numa sociedade.

Os percentuais divulgados após a implementação do Cadastro Nacional de Adoção - CNA - mostram que $80,6 \%$ dos candidatos a adotantes, tem preferência por crianças até 3 anos; $20 \%$ por crianças de 4 a 7 anos e, apenas $0,9 \%$, com idade de 7 até 18 anos, ou seja, os percentuais mostram que o perfil de crianças e adolescentes aptos à adoção, estão longe do perfil procurado pelos adotante, pois , "vivendo nos abrigos do País encontram-se, na maioria, meninos (58,5\%), afrodescendentes $(63 \%)$ e mais velhos, isto é, com idade entre 7 e 15 anos (61,3\%)" (BRASIL, 2006, p. 60), nesta idade, apenas $1,9 \%$ dos adotados mostram interesse.

A pergunta que se impõe é: Como está sendo preservado o direito à convivência familiar e comunitária destas crianças?

O CNA conta com mais de 11.000 pessoas dispostas a adotar e cerca de 2.000 crianças e adolescentes disponíveis, o cálculo matemático simples mostra a cruel realidade -11.000 pretendentes - 80,\% aceitam crianças até 3 anos ou seja 8,866 pretendentes "querem" uma criança até 3 anos. ${ }^{14}$ As 2.000 crianças aproximadamente disponíveis, provavelmente são aquelas fora dos padrões dos 8.866 pretendentes.

O Ministério Público tem atribuições nos processos de adoção e deve zelar pela proteção dos direitos da criança e do adolescente, fiscalizando a efetividade das garantias constitucionais, e, com a limitação imposta, relativa a idade da disposição para a adoção, 12 anos, outro questionamento se impõe: Qual é a resposta para o contingente de crianças abaixo de 12 anos e que não pode ter a expectativa da adoção como condição de garantir a convivência familiar e comunitária? Como o Ministério Público pode efetivar o

\footnotetext{
14 "Ao completar oito meses de criação, o Cadastro Nacional de Adoção revelou um número maior de pais interessados do que crianças para serem adotadas. Os números mostram que existem 12.836 pretendentes a pais, enquanto são apenas 1.887 crianças e adolescentes aptos à adoção. A situação seria favorável à adoção, se não fosse um detalhe: os interessados querem crianças diferentes do que a maioria que aguarda nos abrigos por um pai e uma mãe. [...] No Brasil, 92,4\% das crianças e adolescentes prontas para a adoção possuem mais de três anos e $74 \%$ têm irmãos." Íntegra da notícia disponibilizada na "Agência CNJ de Notícias" em data de 14.01.2009. Disponível em: <http://www.cnj.jus.br/>. Acesso em: 20 mar. 2009.
} 
direito fundamental das crianças até 12 anos e que não tem pretendentes com a intenção de adotá-los?

A possibilidade do reconhecimento da união homoafetiva como entidade familiar importa no reconhecimento do direito destes em requerer em conjunto a adoção de crianças e adolescentes. Esse reconhecimento pode possibilitar a ampliação do número de pretendentes à adoção, consequentemente, amplia a possibilidade da inserção de uma criança ou um adolescente em uma família, efetivando o princípio constitucional da dignidade da pessoa humana, reconhecendo-os como cidadãos.

Quando os sujeitos que atuam no processo de adoção mostram restrições à possibilidade da adoção por homoafetivos em razão de preconceito, não deles, e sim da sociedade: "estou protegendo da situação que é gerada em razão da diferença e minoria em que ele vai se inserir". (S6), e uma preocupação :"[...] Pode ter uma boa aceitação, mas será que a gente ta preparado para este atendimento depois." (S8), procurando justificar a respectiva posição.

A proteção ou eventual receio de atender as situações não podem ser determinantes para afastar a possibilidade da criança ou do adolescente ser inserido num lar, pois o combate ao preconceito somente poderá existir se o debate tomar visibilidade. Com o debate, dúvidas podem ser esclarecidas, posições podem ser apontadas, ou seja, o combate ao preconceito ocorrerá na medida em que se perceber o "falso juízo", do contrário, não se toma uma atitude e se espera que as coisas continuem como estão, e esta atitude não faz parte da definição de cidadania dada pelos próprios sujeitos, de participação, de acesso a direitos, de construção de novas consciências e relações.

Das respostas apresentadas conclui-se que para os sujeitos que atuam no processo de adoção, é melhor a "segurança" do "problema" conhecido, do que talvez, uma solução "que pode vir a dar problema". A contradição aparece, o entrevistado apresenta o receio de eventuais conflitos em adoções homoafetivas, no entanto, reconhece conflitos existentes mesmo nas adoções "normais": [...] Hoje a gente precisa dar auxilio para crianças que foram adotadas que estão em conflito, e a gente precisa dar este apoio, e a gente já não tem nem pra isso[...]." (S8)

Outra contradição do sujeito transparece quando responde que não acompanha o debate da adoção por homoafetivos, apesar de emitir parecer social em processos de cadastramento de pessoas para adoções. Ao questionamento sobre o cadastro de pessoas sozinhas, respondeu: "a gente tem o cadastro solteiros [...] nestes três anos que estou na vara, não teve nenhuma situação que a gente observou que, fosse solteiro, e pudesse ter a situação", pode-se entender, por esta resposta, que talvez não se queira tomar uma posição sobre o tema, e, outra contradição aparece no depoimento quando se avalia própria concepção de cidadania "é todo esse conjunto [...], do cidadão, de direitos, das obrigações, o que você faz, o que você vive está envolvido pra mim na cidadania". (S8). 
Se a criança tem prioridade absoluta, como então deixar esta criança no abrigo porque ela ainda não completou 12 anos?

Outro sujeito, a princípio, deixa o entendimento de que não existe óbice à estas adoções, "[...] já dei, não sei se era homossexual, pode ser [...] é o ideal é o ideal." (S7), após, deixa transparecer algumas dúvidas: "[...] porque, biologicamente sabe que tem um pai e uma mãe, não? Então precisa trabalhar a cabeça da criança [...] elaborar tudo isso, não vai ser fácil. Tudo é possível." (S7).

A possibilidade de confusão na atribuição dos papéis de pai e de mãe, conforme transparece do depoimento do S7 é um dos argumentos que frequentemente pode ser verificado para negar aos homoafetivos o direito à paternidade-maternidade. O modelo mãe - função cuidadora e pai - função normatizadora ainda é muito presente, contudo, a determinação das funções, pertencentes a homem ou mulher é construção social, em razão da cultura e de valores que imperam na sociedade. Fernández e Vilar (2004) in Futtino (2006, p. 155), comparam a monoparentalidade à homoparentalidade para levantar questões a respeito de que se há necessidade de um "um casal heterossexual para a construção da identidade sexual dos filhos pode-se dizer que um filho do sexo masculino criado apenas por sua mãe necessariamente apresentaria dificuldades com sua sexualidade."

De positivo, no posicionamento dos sujeitos que estão envolvidos com o processo é a abertura para o debate, referidos algumas vezes, "Deve-se debater, deve-se falar às claras, deve-se desmistificar a coisa" (S7). Esta abertura pode fazer a diferença e apresentar novas concepções, pois, se num primeiro momento a orientação se dá pelos dados já oferecidos na ordem social, resultando em juízos provisórios, aceitando a possibilidade do debate, esses juízos provisórios podem ser alterados ou corrigidos, eliminando o preconceito (HELLER, 1989, p. 46).

As posições dos demais sujeitos, enquanto militantes, mãe e pai adotivos, demonstram posições positivas em relação a adoção por homoafetivos enquanto forma de priorizar à criança e ao adolescente o direito fundamental de convivência familiar e comunitária. Todos manifestaram concordância, justificando que, esta forma de adoção, pode quebrar preconceitos e incluir crianças e adolescentes como cidadãos, porque "na maioria das vezes são casais dispostos a adotarem crianças mais velhas e sem preconceito sobre raça, cor ou sexo" (S4), e completa exemplificando "tenho acompanhado esse tema de perto, os irmãos de meu filho foram adotados por um casal homoafetivos" (S4).

"Grupo de irmãos" também não é a preferência dos "casais padrão". Receber grupo de irmãos foi a opção de outro sujeito que participou da pesquisa, "[...] Em agosto de 2007 recebi meus filhos, um casal, o menino com 8 anos e uma menina de 4 anos, irmãos."(S5) 
Um dos militantes dos GAAs não mostra preocupação com o fato de ainda não existirem produções teóricas o suficiente para garantir resultados, entende que basta que a paternidade/maternidade sejam exercidos de forma responsável e afetivamente protetoras, garantia essa exigida de qualquer pretendente à adoção, seja homo ou heterossexual, porque, mesmo entre os heterossexuais, muitas vezes verifica-se situações de irresponsabilidades paternais ou maternais.

Para outro sujeito, "casais homo afetivo são participantes da cidadania como qualquer outro que participa da sociedade" (S5), a única preocupação deveria constituir na averiguação, "em cada caso, como cada um se insere neste contexto de cidadão", requisito que confirma a preocupação destes sujeitos com o melhor interesse da criança, que, de fato, é o fator determinante para o deferimento ou não da adoção.

As condições morais e sociais, que consta na resposta de um dos sujeitos, são gerais, independem se são hetero ou homossexuais, "[...] nenhum juiz irá entregar uma criatura para pessoas sem dignidade, sejam homo ou heteros." (S2).

Receios de ordem emocional, de preconceitos ou relativos à sexualidade dos pais, são resolvidos pelo ser humano com conversas, esclarecimentos, debates, conforme explicação de um dos entrevistados,

"O aparecimento da sexualidade nos pais é sempre problemático para os filhos, no caso dos homoafetivos isto também se coloca, as perguntas são constantes e a curiosidade é bem vinda, ou deveria ser bem vinda, isto deve ser falado e por outro lado deve ser mantido um véu de pudor. Falar de sexo não é realizar atos sexuais na frente dos filhos. O que se passa na intimidade de um par diz respeito ao par. Como cada um vai criar o que se passa lá é construção de cada um, é assim que o sexo se realiza na fantasia de cada um. Outro dia meu filho me perguntou no vestiário da natação se não tinha vergonha de ser gay, lhe respondi no ato que quando criança tinha vergonha. Retomei com ele mais tarde para explicar o que era gay ou o que ele achava que era isto? Ele não quis mais falar no assunto e respeitei-o. O que é ser homem ou o que ser mulher são questões que se levam uma vida para serem construídas e são decorrentes do trabalho de cada um. Não são coisas que se podem dar aula, e quando se tenta dar aula disto, se acaba expondo suas fantasias sobre o assunto".(S5)

No Brasil desconhece-se uma pesquisa ${ }^{15}$ que aponte eventuais efeitos do desenvolvimento de crianças e adolescentes inseridas em ambientes

\footnotetext{
${ }^{15}$ Destaque-se para pesquisa realizada pela Associação dos Magistrados Brasileiros, publicada em maio de 2008, na campanha "Mude um destino, campanha da adoção consciente", sobre a percepão da população brasileria sobre a adoção, não ocorreu nenhum questionamento relativo a orientação sexual dos adotantes. Disponível em <http://www.amb.com.br/mudeumdestino/docs/ pesquisa_adocao.pdf $>$. Acesso em 24 jun. 2013. O mesmo ocorre com recente pesquisa do CNJ,
} 
homoparentais, até porque a realidade destas famílias era, até a pouco, invisível. As pesquisas são escassas, mas trabalhos teóricos são produzidos, procurando entender as possibilidades da família homoafetiva, destaca-se DIAS (2008); FUTTINO (2006); UZIEL (2007).

Nada de concreto pode ser usado contra essas famílias e a sua possibilidade/direito de terem filhos, muito menos em relação a tirar o direito de uma criança ou adolescente a crescer num ambiente de afeto e cuidado, ou seja, num ambiente familiar. Futtino (2006, p. 155) apresenta pesquisas empíricas realizadas, demonstrando que o desenvolvimento das crianças criadas por homossexuais apresentam semelhanças com aquelas criadas por heterossexuais, "estas pesquisas afirmam que a média de filhos homossexuais de pais com a mesma orientação sexual segue os padrões gerais, o que coloca a preocupação dos pais não no desenvolvimento do filho, mas no preconceito da sociedade". O preconceito da sociedade se combate com o debate aberto, com a desmistificação e o conhecimento efetivos.

\section{CONSIDERAÇÕES FINAIS}

A pesquisa permitiu sistematizar o debate e resultou na identificação de uma perspectiva positiva para a questão pesquisada, não obstante ainda depender de um processo sociocultural que abra possibilidades à cidadania de crianças, adolescentes e às uniões homoafetivas.

A adoção é a modalidade mais adequada quando se trata de crianças e adolescentes que não mais tem como retornar às suas famílias, no entanto, é um instituto que ainda procura uma delimitação adequada ao tempo presente.

As concepções expressas pelos sujeitos levam a considerar que as perspectivas para enxergar as crianças e os adolescentes como sujeitos de direitos, e, portanto, credores dos direitos fundamentais garantidos constitucionalmente, especialmente a convivência familiar e comunitária ainda são frágeis. Principalmente, do ponto de vista dos sujeitos ligados ao processo, que não obstante saberem da necessidade de não deixar as crianças e adolescentes em abrigos, mostram ainda dificuldade em tomar posições relacionadas à colocação em família substitua, especialmente quando trata-se de entidade familiar que tenha um contorno diverso daquele expresso ao longo dos tempos, ou seja, as uniões formadas por pares homossexuais.

Por outro lado, os sujeitos que representam setores organizados da sociedade civil marcam mudanças neste quadro, mostram preocupação com o abrigamento e reconhecem que as uniões homoafetivas pode ser uma opção a mais para a possibilidade de dar um família as crianças e adolescentes que dela foram privados.

\footnotetext{
"Encontros e desencontros da adoção no Brasil", realizada em 2012 e publicada neste ano de 2013, não há qualquer referência a orientação sexual dos pretendentes, demonstrando a invisibilidade inata ao tema. Disponível em <http://www.crianca.caop.mp.pr.gov.br/arquivos/File/publi/cnj/pesq adocao_brasil.pdf>. Acesso em 24 jun. 2013.
} 
As mudanças somente iniciam no marco de múltiplos contextos, que podem assim ser sintetizados: assumindo a necessidade de cumprir o compromisso assumido e oficializado através do Estatuto da Criança e do Adolescente; construindo uma nova cultura da adoção; entendendo que as configurações das famílias e das funções paterno-maternais não estão predestinadas a homem-mulher;

Tais mudanças podem ocorrer se os objetivos e diretrizes do Plano Nacional de Convivência Familiar e Comunitária forem materializados, para o que, há necessidade de um compromisso tanto do Estado quanto da sociedade, para mudança de comportamentos, prescindindo de uma nova cultura, da construção de novas relações que possam elevar os patamares de consciência e assim incluir cidadãos na dinâmica social.

No decorrer do estudo, observou-se que as perspectivas positivas à adoção por pessoas em uniões homoafetivas, por parte dos sujeitos dos setores da sociedade civil já é uma realidade; contudo, os sujeitos envolvidos no processo da adoção, enquanto profissionais, ainda tem um envolvimento tímido. O ponto contraditório destes sujeitos situa-se exatamente na visão das crianças e adolescentes abrigados versus adoção, pois mesmo reconhecendo o problema da permanência indeterminada das crianças no abrigamento, ao referir-se a eventuais soluções, não trazem a colocação destas crianças e adolescentes em famílias substitutas como uma solução efetiva, e sim apenas, quando citada esta forma, como residual. Lançam as alternativas em políticas públicas para as famílias.

A adoção deve priorizar o interesse da criança e do adolescente ao qual se destina, e, com vistas a prioridade dos interesses deles é que a possibilidade da ampliação do leque de famílias deve ser entendido, incluindo também as uniões homoafetivas, que, não resolverá o problema da criança e do adolescente abrigados, mas a pretensão foi refletir sobre uma alternativa a mais para efetivar a cidadania destas crianças e adolescentes oportunizando a convivência familiar.

\section{REFERÊNCIAS BIBLIOGRÁFICAS}

BARANOSKI, Maria Cristina Rauch. A Adoção em Relações Homoafetivas. Ponta Grossa: Editora UEPG, 2011. 170p.

BRASIL. Cadastro Nacional de Adoção. Agência CNJ de Notícias em data de 14.01.2009. Disponível em: <http://www.cnj.jus.br/>. Acesso em 20 mar. 2009.

Constituição da República Federativa do Brasil de 05 de outubro de 1988. Disponível em <http://www.planalto.gov.br/ccivil_03/Constituicao.htm>. Acesso em 20 abr. 2009.

$\overline{\text { Adolescente). }}$

Lei Federal no 8.069, de 13 de julho de 1990 (Estatuto da Criança e do

Presidência da República. Secretaria Especial de Direitos Humanos. Conselho Nacional dos Direitos da Criança e do Adolescente. Plano Nacional de Promoção, Proteção e Defesa do Direito de Crianças e Adolescentes à Convivência Familiar e Comunitária / Secretaria Especial dos Direitos Humanos. Brasília-DF: Conanda, 2006. 
CORRÊA, Darcísio. A Construção da Cidadania: reflexões histórico-políticas. 3. ed., ljuí: Ed. UNIJUİ, 2002. 240p.

COSTA, Lúcia Cortes da. Os Impasses do Estado Capitalista: uma análise sobre a reforma do Estado no Brasil. São Paulo: Cortez, 2006.

DAGNINO, Evelina (org.). Cultura e Política nos Movimentos Sociais Latino-americano. Belo Horizonte: Editora UFMG, 2000.

DIAS, Maria Berenice. Família Homoafetiva. In: BARBOSA, Á. A.; VIEIRA, C. S. (Coords.). Direito de Família. São Paulo: Editora Revista dos Tribunais, 2008.

FUTINO, Regina Silva; MARTINS, Simone. Adoção por Homossexuais: uma nova configuração familiar sob os olhares da psicologia e do direito. Aletheia. [online]. dez. 2006, no 24 [citado 16 Março 2009], p. 149-159. ISSN 1413-0394. Disponível em: $<$ http://pepsic.bvs-si.org.br/scielo.php?script=sci_arttext\&pid=S1413-03942006000300014 \&lng=pt\&nrm=iso>. Acesso em: 16 mar. 2009.

GROENINGA, Giselle Câmara. Generalidades do Direito de Família. Evolução Histórica da Família e Formas Atuais de Constituição. In: BARBOSA, Á. A.; VIEIRA, C. S. (Coord). Direito de Família. São Paulo: Saraiva, 2008 (Coleção Direito Civil, V. 7).

GROSSI, Mirian Pillar. O Pai não está Desaparecendo, o que temos é uma transformação de papéis. Revista do Instituto Humanitas Unisinos, ed. 287, 02.03.2009. Disponível em <http://www.unisinos.br/ihuonline/index.php?option=com_tema_capa\&ltemid=23\& task =detalhe\&id=597> . Acesso em: 15 mar. 2009.

HELLER, Agnes. O Cotidiano e a História. Rio de Janeiro: Editora Paz e Terra S/A, 1989. IPEA. Instituto de Pesquisa Econômica Aplicada. Disponível em: <www.http//ipea.gov.br>. Acesso em: 25 jul. 2008.

LESSA, Renato. Dicionário do Pensamento Social do Século XX. Rio de Janeiro: Zahar Editores, 1996.

MARSHALL, T. H. Cidadania, Classe Social e Status. Trad. Meton Porto Gadelha. Rio de Janeiro: Zahar Editores, 1967.

MARTINELLI, Maria Lúcia. O Uso das Abordagens Qualitativas na Pesquisa em Serviço Social. Núcleo de Estudos e Pesquisa sobre Identidade - NEPI, 1994.

MELLO, Luiz. Familismo (anti) Homossexual e Regulação da Cidadania no Brasil. Estudos Feministas, Florianópolis, 14(2): 248, maio/ago. 2006. Disponível em $<$ http://www.scielo.br>. Acesso em 23 maio 2008.

PURETZ, Andressa; LUIZ, Danuta Estrufika Cantóia. Adoção Tardia: desafios e perspectivas na sociedade contemporânea. In Emancipação: Universidade Estadual de Ponta Grossa, Departamento de Serviço Social. Ponta Grossa: Editora UEPG, v. 1, $\mathrm{n}^{\circ}$ 1, 2007.

SANDOVAL, Salvador A. M. Algumas Reflexões sobre a Cidadania e Formação de Consciência Política no Brasil. In SAWAIA, Bader. As Artimanhas da Exclusão: análise psicossocial e ética da desigualdade social. Petrópolis: Vozes, 1999.

SANTA CATARINA, Manual do Promotor de Justiça da Infância e da Juventude. Centro de Apoio Operacional da Infância e Juventude do Ministério Público de Santa Catarina. Florianópolis: Coordenadoria da Comunicação Social, 2008.

SILVA, Enid Rocha Andrade da. O Direito à Convivência Familiar e Comunitária: os abrigos para crianças e adolescentes no Brasil. Brasília: IPEA/CONANDA, 2004. Disponível em <http://www.ipea.gov.br/sites/000/2/livros/direitoconvivenciafamiliar_capit 2.pdf.>. Acesso em 19 jun. 2013. 
TRIVIÑOS, Augusto Nibaldo Silva. Introdução à Pesquisa em Ciências Sociais: a pesquisa qualitativa em educação. São Paulo: Atlas, 1987.

UZIEL, Anna Paula. Homossexualidade e Adoção. Rio de Janeiro: Garamond, 2007.

WANDERLEY, Mariângela Belfiore. Refletindo sobre a Noção de Inclusão. In SAWAIA, Bader. As Artimanhas da Exclusão: análise psicossocial e ética da desigualdade social. Petrópolis: Vozes, 1999.

WEBER, Lídia Natalia Dobrianskyj. Laços de Ternura: pesquisas e histórias de adoção. 2. ed., rev. e atual. Curitiba: Juruá, 2000, 218p. 